\title{
The Common Play Skills of Children with Autism Spectrum Disorder: Evidence from Saudi Arabia
}

Article History:

Received 03.09.2020

Received in revised

form 12.06 .2021

Accepted

Available online

01.10.2021

\section{Saad Yahya Athbah}

\begin{abstract}
This study investigated the common play skills autism spectrum disorder and statistical differences in the playing skills of autistic children disorder that attribute to disorder severity and sex of the child. The study sample consisted of (163) teachers and parents of students with autism registered in government centers and institutes for the Ministry of Education and the Ministry of Social Affairs in Jeddah for the academic year 2020/2021, who were randomly selected. A questionnaire was adopted including (52) items divided into (4) dimensions to collect data about the playing skills of autistic children disorders, including basic play skills, individual play skills, symbolic play skills, and playing with others skills. The findings revealed that autistic children condition have generally moderate play skills. The findings also revealed that there are no statistically significant variations in playing skills between males and females with an autism spectrum disorder. In addition, the findings showed that there are statistically significant variations in play skills between autistic children disorders related to the severity of the disorder favor to children with simple disorder.
\end{abstract}

(C) IJERE. All rights reserved

Keywords: Play skills, basic play skills, individual play skills, symbolic play skills, autism spectrum disorder

INTRODUCTION

The childhood stage is considered the most important stage of a person's life. In childhood, the child be more accepting of the guidance that contributes to building his future personality, as the child's abilities grow, and talents are defined at this stage of a person's life (Cesur \& Odluyurt, 2019). The stage of early childhood is the most crucial in a person's existence due to its flexibility, ability to learn, and development of a variety of skills and talents, where children tend to explore and experiment in this stage (Sucuoglu, Bakkaloglu, Demir \& Atalan, 2019). Play is a considerable feature of children as takes up a large portion of their time that led contributes to the formation and construction of the child's personality from all sensory, motor, social, emotional, and mental aspects (Szabó, 2014). Through play, the child learns about the outside world, environment, his and others' roles, as well as the culture, language, values, and ethics of his society (Bundy, 2012). Thiemann-Bourque, Johnson, and Brady (2019) indicated that through various playing skills, the children learn about forms, sizes, and colors as well as what differentiates the objects in their environment in terms of the features that they combine, functions and relationships, which lead to enhance his mental abilites by providing him with a diverse range of information about the environment around him and beginning of teaching him thinking skills. Therefore, delayed, or abnormal development in play behaviours inevitably affects the development of these skills during life stages (Cesur \& Odluyurt, 2019). Normal children develop play skills naturally, whereas autistic children do not, and their development may be significantly atypical (Jung \& Sainato, 2015). Ahmad (2012) mentioned that this lack of play skills of autistic children is due to many reasons including the lack of motivation of these children to play because of their lack of common attention skills, the disorder in perception, and the weak ability to form symbols in addition to a lack of awareness of shared hypothetical situations and a weak ability to imitate. These and other play-related difficulties that most autistic children suffer from increase their social isolation and impose restrictions on them forcing them to adhere to those routine activities that they have been used to (Vousden, WilkesGillan, Cordier \& Froude, 2019). Many researchers such as (Szabó, 2014; Jung \& Sainato, 2015; Cesur \& Odluyurt, 2019; Thiemann-Bourque, et al., 2019; Vousden et al., 2019) emphasized that most autistic children spend little time playing games with low levels. For most of them, playing is characterized by repetition and monotony in performance and the misuse of its tools properly and functionally, and many of them spend a lot of time in isolated play and show less interaction and communication in different playing situations, in addition to their lack of ability to automatic imaginative play and social play appropriate to the level of development.

saadathbaha@gmail.com, orcid.org/0000-0003-2813-0336, Jeddah University 


\section{International Journal of Educational Research Review}

Autism children acquire playing skills is very difficult because they do not learn easily through causal observation, as they need flexible and unstructured skills, researchers interested in improving play skills and behaviors among autistic children, given that is the most effective method in acquiring skills quickly and at the lowest cost in time and effort (Hatzenbuhler, Molteni \& Axe, 2019; Szabó, 2014;). Many of the previous literature on autistic children have mentioned a lot about the play in these children, as many of them show abnormal patterns and characteristics that differ from normal children's play (Hatzenbuhler et al., 2019; Vousden et al., 2019; Kent et al., 2020). Despite previous studies that have been conducted to reveal the skills and patterns of play in these children, they remain few and narrow in scope (Cesur \& Odluyurt, 2019; Vousden et al., 2019).

Play

Defining the concept of "play" is difficult, due to its multifaceted impact on child growth (Cesur \& Odluyurt, 2019). The "play" is considered a normal part of the life of a child and has an abstract structure and a variety of forms (Vousden et al., 2019). Play is an approach for ensuring communication of children and learns new knowledge about their world based on different aspects of current knowledge base, acquiring experience, creativity, and skills of cooperation (Ulke-Kurkcuoglua, Bozkurtb \& Cuhadarc, 2015). Bundy (2012) defined play as the primary career of childhood that is necessary for a child's growth, safeguarding well-being and health, and evolving mutual friendship. Kent et al. (2020) defined play as a deal between environment and individual that includes essential motivation, internal monitor, and freedom to suspend reality.

For children who are naturally developing, the skill to play with objects is developed through four complex stages during the first three years of life (Flippin \& Watson, 2011; Szabó, 2014; Hatzenbuhler et al., 2019). The first stage is an exploratory play that arises between 4 and 6 months of the child's age. Children begin to explore the properties of toys at this age by using movements such as banging, mouthing, and falling (Szabó, 2014; Hatzenbuhler et al., 2019). The second stage is relational play that arises between 6 and 12 months of the child's age. Children begin to mix toys in increasingly progressed methods such as ring or block-stacking, putting and taking things out of containers (Flippin \& Watson, 2011; Hatzenbuhler et al., 2019). The third stage is a functional play that arises between 12 and 16 months of the child's age. Children begin able to use toys and miniatures in the manner intended, such as sweeping with a toy broom (Szabó, 2014; Hatzenbuhler et al., 2019). Finally, the fourth stage is a symbolic play that arises between 16 and 30 months of the child's age. Children who engage in symbolic play will swap one object for another such as use bananas as a phone, and to employ fictitious characteristics such as cold and hot, and imaginative and fantasy games, as well as complex, pretend schemas (Flippin \& Watson, 2011; Hatzenbuhler et al., 2019).

\section{Play and Autism Spectrum Disorder}

Autism spectrum disorder is a prevalent developmental disease that affects one in every 160 children globally (Vousden et al., 2019). Autism spectrum disorder manifests itself in the first three years of life and is marked by repetitive behaviors and social isolation (American Psychiatric Association, 2013). The social contract limitations are slowness in the development of language, difficulty conducting a conversation, repetitive or atypical language, and play that isn't suitable for the child's development (Ulke-Kurkcuoglua et al., 2015). Fixed desires, repetitive and concrete habits, decreased quality of symbolism, lack of versatility and impaired skills of social are all lineaments of different play styles for autistic children (Kent et al., 2020). According to MacDonald et al. (2009) turn-taking, reorienting actions away from desirable goals, a reduction in symbolic consistency, and as well as surrendering control over favorite play activities are all difficulties with components of play for autistic children. Improvements in play skills lead to more productive social experiences and less inappropriate activities of autistic children (Jung \& Sainato 2013).

In light of those possible difficulties, it can be particularly beneficial to provide autistic children in inclusive environments with opportunities to engage with children who have more developed play and social skills (Hampshire \& Hourcade, 2014). Understanding the advancement of children's learning to play is one way to help autistic children improve their skills. The agreeable advancement play skills are as follows (Charlesworth, 2011; Hampshire \& Hourcade, 2014; Hamdan, 2017): Basic playing skills: 


\section{International Journal of Educational Research Review}

it is a primary form of play where the child plays freely and automatically far from the rules governing the play, where every child plays as he wants.

- Individual play skills: it is the play that depends on self-guidance, as it is an independent play that the child relies on himself to do

- Symbolic play skills: it is the play in which the child moves to play through the symbols imagines and interacts with them so that he gives each game a role and creates a special scenario for playing.

- Playing skills with others: it is the play in which the child moves to play in groups to achieve a mutual goal.

\section{Previous Studies}

Flippin and Watson (2011) examined object play skills of autistic children. At four stages (symbolic, functional, relational, and exploratory), frequency of play of children was compared through unsupported play circumstances, father-child, and mother-child. Also, relationships between responsiveness parents of play and their children's ability to play with objects were examined. The findings showed that the children appeared to participate mothers in relational play and unsupported play more than fathers. Also, the findings showed that the use of receptive verbal activities was highly associated with both mothers and fathers can engagement in higher-level of object play; however, higher-level of object play was only linked to the use of fathers of behaviors of responsive play. The study of Brady, Fleming, and Burke (2012) aimed to compare play between (35) autistic children and (38) developmentally delayed children and who spoke approximately twenty words. The study's findings revealed that no statistically significant differences in the play behaviors of the participating children between the two groups of the participating children. Autistic children in traditional games involve grouping things together, and the results also showed a significant association between play, language, and cognitive measures. The study of Lam and Yeung (2012) examined the symbolic play skills and cognitive difficulties of (12) autistic children and (12) children with normal developmental development. Autistic children showed much fewer playing skills than their peers with normal developmental, and they also had clear difficulties on measures of mind theory and central correlation theory, and there were no clear difficulties on the scale of executive function. Fazlioglu (2013) conducted a study aimed at comparing the ancient playing skills of autistic children and those with mental disabilities with normal children in the ages of (60-72) months. The results showed that the college score on the rating scale for playing skills was moderate, and the mean scores of the study sample members of normal children were higher than the scores of individuals with mental disabilities and autistic children, and there were no statistically significant differences in the mean scores for children with disabilities, and the playing skills of children with mental disabilities and those with autism spectrum disorder are weaker and less What are normal children. Szabó (2014) investigated the differences of object play between a boy with autism spectrum disorder and a mental age-matched child with typical development. The results revealed that the typically developed child tended to engage in imaginative play offers by the mother. The autistic boy's focus was limited, and he required more details about the methods used to understand it. The autism spectrum disorder child showed a willingness to depend on pictures in the play activity. The typical development spontaneous child's play represented a more realistic and adaptable understanding of the world around him (mental representations that are dynamic), While the autistic child preferred collections of single pictures (information for cognition that is simpler and more static) by groups. Hamdan (2017) investigated the typical play traits in autistic children to determine if there was a link between them and specific variables. The findings showed that all measures of typical play traits in autistic children were poor. The findings also revealed that there are no statistically significant changes in all dimensions of play skills due to degree of autism spectrum condition; this suggests that regardless of the degree of the disease, autistic children have similar playing characteristics. Thiemann-Bourque et al. (2019) compared the play of autistic children and children with normal development that was balanced in cognitive skills and language. Findings showed there were no variations in indiscriminate behaviour, object interest, or functional play. A few autistic children met the requirements for emerging or perfected symbolic 


\section{International Journal of Educational Research Review}

play. According to the findings, as compared children without disabilities and autistic children can have similar functional play skills but have difficulty transitioning to new environments.

Substantially, children with autism spectrum disorder exhibit weaker play skills than their normally developing peers. However, no study has investigated the perspectives of teachers and parents of children with autism spectrum disorder on their play skills. Knowing the perspectives of teachers of children with autism spectrum disorder on the acquisition of play skills may help you have a better understanding of the problem. However, it is equally critical to comprehend the views of parents who have children with autism spectrum disorder, as well as the challenges they face and the resources they require. The current study tries to support the theoretical frameworks and previous literature on detecting and identifying play skills of autistic children and studying some of the relevant variables that may affect play in these children. Therefore, the study attempts to achieve its results by answering the following questions:

- What are the common play skills of autistic children?

- Are there statistically significant differences $(0.05 \geq \alpha)$ in the play skills of autistic children due to the severity of the disorder and the sex of the child?

\section{Method}

This study used a quantitative approach and a descriptive method, it attempted to generate a systematic, actually, and meticulous description of a population's facts and characteristics. The object of descriptive quantitative research is to clarify or define the characteristics of the state or topic of investigation then presenting the data in an analytic format (Saunders, Lewis \& Thornhill, 2016).

Population and Sample

The study population consists of all teachers and parents of students with autism of both sex, age between 3-16 years, and with various severity of the disorder (simple, moderate and strong), who are registered in private and government centers and institutes of Ministry of Education and the Ministry of Social Affairs in Jeddah for the academic year 2020/2021. As for the study sample, it reached (163) teachers and parents of students with autism who were randomly selected.

\section{Research Instrument}

To achieve the purpose of the study, which is to determine the play skills of autistic children disorder, questionnaires were built by reviewing previous literature related to play in autistic children. The questionnaire of this study was mainly based on prepared by Hamdan (2017) that included two-part. The first part includes 'sex, age, and severity of the disorder' of autistic children. The second part includes (52) items divided into (4) dimensions and includes basic play skills including items (1-14), individual play skills including items (15-26), symbolic play skills including items (27-34), and playing skills with others including items (35-52), each item used a five-point Likert Scale ranging from "1" (very low) to"5" (very high).

Instrument Validity

To verify the validity of the questionnaire, the arbitrators' validity method was used by presenting the questionnaire to a set of arbitrators with expertise and experience in the field of autism spectrum disorder from institutions and centres for children with autism spectrum disorder, and universities. The arbitrators agreed regarding the suitability of the questionnaire to achieve the objectives of the study, as the duplicate items that were not appropriate for the dimension were deleted, and a number of items were added, and some inappropriate items were amended in terms of wording, the questionnaire in final form consisted of (52) items, divided into (4) dimensions.

Instrument Reliability

The reliability of the instrument means that when using the same instrument on the same sample in the same circumstances, the same results are obtained every time. Internal accuracy and responses of respondents were measured using Cronbach alpha. As shown in Table1, a value of (60 percent) or higher indicated the responses of respondents are reliable (Bryman \& Bell,2011; Saunders et al., 2016). 
International Journal of Educational Research Review

Table (1): Test of Cronbach's Alpha

\begin{tabular}{cc}
\hline The Variables & $\begin{array}{c}\text { Value of Cronbach } \\
\text { Alpha }\end{array}$ \\
\hline Basic playing skills & 0.766 \\
\hline Individual play skills & 0.757 \\
\hline Symbolic play skills & 0.821 \\
\hline Playing skills with others & 0.895 \\
\hline All items & 0.825 \\
\hline
\end{tabular}

The internal consistency coefficient values for the study's measurements were high, as shown in Table1, ranging between (0.757-0.895). This means that the Cronbach Alpha coefficient is greater than (0.60) for all parts of the questionnaire. This result emphasizes that the items in the instrument of the study are internally consistent.

Data Analysis

The researcher used SPSS software to answer the study's questions by using means, independent sample" $t$ " test, and One Way ANOVA. When comparing two ways, the independent sample" $t$ " test is used, and when comparing three or more means, One Way Anova is preferred (Cuevas, Febrero \& Fraiman, 2004). Means were used to explaining the findings according to Table (2).

Table (2: Explaining Means

\begin{tabular}{cc}
\hline Mean & Information \\
\hline $1,00-2.33$ & Disagree (DA) \\
\hline $2.34-3.67$ & Moderate Agree (MA) \\
\hline $3.68-5.00$ & Agree (A) \\
\hline Source: (Bryman \& Bell, 2011)
\end{tabular}

\section{Results}

Respondents Profile

To describe the profile of the autistic children in terms of 'sex, age, and severity of the disorder', a descriptive analysis was used. The majority of children were male representing $52.8 \%$, while $47.2 \%$ were female, respectively, as shown in Table 3. about age, table 3 showed that the vast majority have age between $6-10$ years with a rate of $50.9 \%$, while $30.1 \%$ of children have age between $11-16$ years, and $19.0 \%$ of children have age between 3-5 years. Concerning the severity of the disorder of children, $62.0 \%$ of children have a moderate disorder, as well as $20.2 \%$ of children ${ }_{L}$ have a simple disorder, while $17.8 \%$ of children have a strong disorder.

Table 3. The children Profile (N=163)

\begin{tabular}{cllcc}
\hline Variables & Category & $\mathbf{N}$ & $\%$ \\
\hline \multirow{2}{*}{ Sex } & Male & 86 & 52.8 \\
& Female & 77 & 47.2 \\
\hline \multirow{3}{*}{ Age } & 3-5 years & 31 & 19.0 \\
& 6 - 10 years & 83 & 50.9 \\
& 11-16 years & 49 & 30.1 \\
\hline \multirow{2}{*}{ the severity of the disorder' } & Simple & 33 & 20.2 \\
& Moderate & 101 & 62.0 \\
& Strong & 29 & 17.8 \\
\hline
\end{tabular}

\section{Research Question One}

To answer the first question of the study, means and standard deviations were used to measure each item of autistic children's play skills. 


\section{International Journal of Educational Research Review}

\begin{tabular}{|c|c|c|c|c|}
\hline $\mathbf{N}$ & Item & Mean & St.dev & Result \\
\hline & Basic playing skills & & & \\
\hline 1 & $\mathrm{He} /$ she able to sit alone for five minutes & 3.91 & 1.10 & A \\
\hline 2 & He/ she able to pay attention to the sounds made by some toys and games & 3.60 & 1.09 & MA \\
\hline 3 & $\mathrm{He} /$ she can imitate the movement of some animated games & 3.29 & 1.12 & MA \\
\hline 4 & He/she able to follow the game and move it in any direction & 3.31 & 1.01 & MA \\
\hline 5 & $\mathrm{He} /$ she able to control holding pens or small tools & 3.52 & 1.12 & MA \\
\hline 6 & $\mathrm{He} /$ she able to transfer games from one place to another & 3.55 & 1.16 & MA \\
\hline 7 & $\mathrm{He} /$ she can hide the games in different places and get them again & 3.20 & 1.21 & MA \\
\hline 8 & $\mathrm{He} /$ she is able to hold various toys and games and hold them in his hand. & 3.63 & 1.17 & MA \\
\hline 9 & $\mathrm{He} /$ she can open and use games that need an activation key & 3.84 & 1.04 & A \\
\hline 10 & $\mathrm{He} /$ she can open and close the game and the doors or slots it contains & 3.42 & 1.00 & MA \\
\hline 11 & $\mathrm{He} /$ she able to play with different toys and games properly & 3.47 & 1.13 & MA \\
\hline 12 & $\mathrm{He} / \mathrm{she}$ can remember the names of the games and toys he plays with. & 3.45 & 1.04 & MA \\
\hline 13 & $\mathrm{He} /$ she can store the toys in the cupboard and take them again & 3.34 & 1.39 & MA \\
\hline \multirow[t]{3}{*}{14} & $\mathrm{He} /$ she can pay attention to the people speaking in front of him & 3.44 & 1.36 & MA \\
\hline & Total & 3.50 & 0.57 & MA \\
\hline & Individual play skills & & & \\
\hline 15 & He/she able to place games and dolls next to each other in their sequence & 3.66 & 1.16 & MA \\
\hline 16 & $\mathrm{He} / \mathrm{she}$ able to use cubes to build shapes and figures & 3.40 & 1.29 & MA \\
\hline 17 & $\mathrm{He} /$ she able to transfer water from one cup or bowl to another cup or bowl & 3.32 & 1.29 & MA \\
\hline 18 & $\mathrm{He} /$ she can play with the beads as required & 3.47 & 1.27 & MA \\
\hline 19 & $\mathrm{He} /$ she able to complete 4,5 , or 6 puzzle game shapes without errors & 3.71 & 1.21 & A \\
\hline 20 & $\mathrm{He} /$ she able to hold pens and doodle with them or scribble on paper & 3.66 & 1.26 & MA \\
\hline 21 & $\mathrm{He} /$ she can draw lines and circles on the papers & 3.09 & 1.42 & MA \\
\hline 22 & $\mathrm{He} /$ she able to recognize similar games according to genre or color & 3.14 & 1.33 & MA \\
\hline 23 & $\mathrm{He} /$ she can place similar pictures with each other & 3.54 & 1.29 & MA \\
\hline 24 & $\mathrm{He} /$ she able to solve some easy puzzles related to a game & 3.43 & 1.29 & MA \\
\hline 25 & $\mathrm{He} /$ she can fill the cubes in its box after playing with it & 2.60 & 1.37 & MA \\
\hline \multirow[t]{3}{*}{26} & $\mathrm{He} /$ she able to use scissors to cut different papers & 3.14 & 1.44 & MA \\
\hline & Total & 3.35 & 0.68 & MA \\
\hline & Symbolic play skills & & & \\
\hline 27 & $\mathrm{He} /$ she able to engage in play for a long time & 4.17 & 1.00 & A \\
\hline 28 & $\mathrm{He} /$ she able to take care of the games that are available to him & 3.87 & 1.28 & A \\
\hline 29 & $\mathrm{He} /$ she can play games according to their function and purpose in more than one way & 3.76 & 1.27 & A \\
\hline 30 & $\mathrm{He} /$ she able to provide an opinion on the games offered to them & 3.91 & 1.17 & A \\
\hline 31 & $\mathrm{He} /$ she able to play more than one game at the same time in an integrated approach & 3.92 & 1.08 & A \\
\hline 32 & $\mathrm{He} /$ she able to describe some toys or games using his/her imagination & 4.10 & 1.07 & A \\
\hline 33 & $\mathrm{He} /$ she able to give creative ideas when playing a game & 3.56 & 1.43 & MA \\
\hline \multirow[t]{3}{*}{34} & $\mathrm{He} /$ she able to imagine the presence of people around him during playing & 3.55 & 1.30 & MA \\
\hline & Total & 3.86 & 0.81 & A \\
\hline & Playing skills with others & & & \\
\hline 35 & $\mathrm{He} /$ she can dance to various songs & 3.37 & 1.22 & MA \\
\hline 36 & $\mathrm{He} /$ she able to ride a three-wheeled bike & 3.25 & 1.31 & MA \\
\hline 37 & $\mathrm{He} /$ she able to ride a scooter & 3.09 & 1.36 & MA \\
\hline 38 & $\mathrm{He} /$ she able to throw the ball 10 feet and catch up & 3.23 & 1.33 & MA \\
\hline 39 & $\mathrm{He} /$ she able to kick the ball with his feet and catch up & 3.60 & 1.26 & MA \\
\hline 40 & $\mathrm{He} /$ she can build clay figures with other children who play with him/ her & 3.58 & 1.27 & MA \\
\hline 41 & $\mathrm{He} /$ she able to swim in swimming pools & 2.66 & 1.34 & MA \\
\hline 42 & $\mathrm{He} /$ she can throw the ball upwards as if he is playing volleyball or basketball & 2.93 & 1.37 & MA \\
\hline 43 & $\mathrm{He} /$ she can glide on shoes with moving wheels & 3.72 & 1.25 & $\mathrm{~A}$ \\
\hline 44 & $\mathrm{He} /$ she able to sing a poem together with a group of children & 3.43 & 1.15 & MA \\
\hline 45 & $\mathrm{He} /$ she able can join a certain game with another child & 3.36 & 1.30 & MA \\
\hline 46 & $\mathrm{He} /$ she able to use signs and movements with a group of children & 3.39 & 1.24 & MA \\
\hline 47 & $\mathrm{He} /$ she able to participate in a theatrical show with another child & 3.91 & 1.04 & $\mathrm{~A}$ \\
\hline 48 & $\mathrm{He} /$ she can collaborate with a group of children in a game & 3.93 & 1.02 & A \\
\hline 49 & $\mathrm{He} /$ she able to enjoy playing with a group of children & 3.51 & 1.29 & MA \\
\hline 50 & $\mathrm{He} /$ she can call people to play with him/her & 3.52 & 1.29 & MA \\
\hline 51 & $\mathrm{He} /$ she can pretend to be a mother or a father of a game that he cares about it & 3.38 & 1.23 & MA \\
\hline \multirow[t]{3}{*}{52} & $\mathrm{He} /$ she can pretend he/ she is someone else like Spiderman or Spiderman & 3.25 & 1.31 & MA \\
\hline & Total & 3.39 & 0.75 & A \\
\hline & Over all & 3.52 & 0.39 & A \\
\hline
\end{tabular}

Table 4 shows that the value of the mean of autistic children's play skills was (3.52), with a standard deviation of (0.39). This means that play skills of autistic children are moderate from point of view of teachers and parents of students with autism who are registered in government and private centers and institutes of the Ministry of Education and the Ministry of Social Affairs in Jeddah. The researcher 


\section{International Journal of Educational Research Review}

explains these results that autistic children suffer from deficiencies in communication skills, and they are characterized by inflexibility in behavior and difficulty in the ability to adapt to change. This result is in agreement with the studies of Flippin and Watson (2011); Fazlioglu (2013); Szabó (2014), but disagrees with the study of Hamdan (2017); Thiemann-Bourque et al. (2019).

Item 1, which states, "He/she able to sit alone for five minutes" has highest means score among items of the basic playing skills of autistic children with (3.91). Item 9, which states, "He/she can open and use games that need activation key" has the second-highest mean score among the items with (3.84) While item 7, which states, "He/she can hide the games in different places and get them again" has lowest mean score among the items of autistic children's basic playing skills (3.20). This can refer to that the nature of the typical and behavioral characteristics that make autistic children sit and stay for long periods while performing the activity of play, and one of the general characteristics of autistic children is attachment to tools and things, so it is not surprising to look and pay attention to the sounds emanating from them. On the other hand, there are the social interaction difficulties these children face that make them unable to pay attention to others or imitate their movements, whether in play situations or elsewhere. This result agrees with studies of Szabó (2014) and Hamdan (2017).

Table 4 further revealed that the mean score of individual play skills of autistic children is moderate from point of view of teachers and parents of students with autism who are registered in government and private centers and institutes of the Ministry of Education and the Ministry of Social Affairs in Jeddah was moderate with (3.35) and standard deviation of (0.68). Items 15, 16 which states, "He/she able to place games and dolls next to each other in their sequence", " He/ she able to hold pens and doodle with them or scribble on paper" respectively, has highest means score among items of individual play skills of autistic children with (3.66). While item 25, which states, "He/ she can fill the cubes in its box after playing with it" has lowest mean score among items of individual play skills of autistic children with (2.60). This result may be interpreted according to the researcher's point of view to the routine, restrictive, and specific behavioral characteristics that these children are characterized by that make them use toys according to a routine and specific pattern and thus arrange them next to each other, and their goal may not be to place the games in a specific order and play with them functionally, but rather Because of those behaviors. Also, their ability to use blocks is due to the fact that because such kinds of behaviors and games are characterized as routine behaviors and thus are preferred by autistic children. The reason can also be attributed to poor coordination and visual-motor coordination skills that may be characteristic of many autistic children disorder, especially severe cases and cases that are accompanied by mental disabilities. This finding is congruent with Flippin and Watson (2011); Szabó (2014) and Hamdan (2017).

In addition, Table 4 revealed that mean score of the symbolic play skills of autistic children disorder of autistic children is high from point of view of teachers and parents of students with autism who are registered in government and private centers and institutes of the Ministry of Education and the Ministry of Social Affairs in Jeddah was moderate with (3.86) and standard deviation of (0.81). Item 27, which states, "He/ she able to engage in play for a long time" has highest means score among items of the symbolic play skills of autistic children disorder (4.17). Item 32, which states, "He/ she able to describe some toys or games using his/her imagination" has the second value of the means among the items of the symbolic play skills of autistic children with (4.10). While item 34, which states, "He/ she able to imagine the presence of people around him during playing" has lowest mean score among the items of autistic children with (3.55). This result is explained, according to the researcher's point of view, that one of general characteristics of autistic children is a constant preoccupation with things and behaviors for long periods, just as play represents behavior for an autistic child, and that tools that child plays with represent material things, it is not Be sure to engage in it and last for long periods that may last many hours. Also, one of the most prominent behavioral characteristics of autistic children is a concern for things more than people, and this is what much previous literature has indicated about the general characteristics of autistic children, and since games constitute something and a material component, then there is no doubt that autistic children will perform highly in this type of skill. This finding is congruent with Szabó (2014), but disagrees with the study of Lam and Yeung (2012); Hamdan (2017), and Thiemann-Bourque et al. (2019). 


\section{International Journal of Educational Research Review}

As regards playing skills with other of autistic children, the findings revealed that mean score was (3.39) with a standard deviation (3.39) This indicates that playing skills with other autistic children from point of view of teachers and parents of students with autism who are registered in government and private centers and institutes of the Ministry of Education and the Ministry of Social Affairs in Jeddah were moderate. Item 48 , this states, "He/ she can collaborate with a group of children in a game" has highest means score among items of playing skills with other autistic children (3.93). Item 47, which states, "He/ she able to participate in a theatrical show with another child" has the second-highest mean score among the items of playing skills with other autistic children with (3.91). While item 41, which states, "He/ she able to swim in swimming pools" has lowest mean score among the items of playing skills with other of autistic children with (2.66). This finding is congruent with Thiemann-Bourque et al. (2019) but disagrees with the study of Flippin and Watson (2011) and Hamdan (2017).

Research Question Two

The independent sample ' $t$ ' test and one-way ANOVA were used to determine the significance of statistical differences of the play skills of autistic children attribute to the severity of the disorder and the sex of the child.

Table 5. Independent Samples T- test of sex

\begin{tabular}{ccccccc}
\hline $\begin{array}{c}\text { The } \\
\text { Variables }\end{array}$ & N & Mean & St.dev & df & t & Sig \\
\hline Male & 86 & 3.61 & 0.38 & 161 & 3.132 & 0.976 \\
Female & 77 & 3.43 & 0.38 & & & \\
\hline
\end{tabular}

Table (5) showed that the mean of male for play skills of autistic children was (3.61) and the mean of female for play skills of autistic children was (3.43). In addition, the Sig of two groups of gender is (0.976), which means that there is no significant impact of sex according to point of view of teachers and parents of students with autism who are registered in government and private centers and institutes of the Ministry of Education and the Ministry of Social Affairs in Jeddah. This result converges with the results of Hamdan (2017).

Table 6. ANOVA test of the Severity of the Disorder

\begin{tabular}{ccccccc}
\hline $\begin{array}{c}\text { The } \\
\text { Variable }\end{array}$ & Groups & Sum of Squares & df & Mean Square & F & Sig \\
\hline $\begin{array}{c}\text { Severity } \\
\text { of the } \\
\text { Disorder }\end{array}$ & $\begin{array}{c}\text { Between } \\
\text { groups }\end{array}$ & 1.092 & 2 & .546 & 3.736 & 0.026 \\
\cline { 2 - 7 } & Within groups & 23.382 & 160 & .146 & & \\
\cline { 2 - 7 } & Total & 24.474 & 162 & & & \\
\hline
\end{tabular}

Table (6) showed that there are differences among groups according to the severity of the disorder. Where, the Sig is (0.026), which indicates a statistically significant effect $(\alpha \leq 0.05)$ of the severity of the disorder based on point of view of teachers and parents of students with autism who are registered in government and private centers and institutes of the Ministry of Education and the Ministry of Social Affairs in Jeddah. This result is inconsistent with the study of Hamdan (2017).

The following table also shows results of the Scheffe test to reveal differences between the means of play skills of autistic children according to the severity of the disorder.

Table 6. Scheffe test

\begin{tabular}{cccc}
\hline Variable & Groups & Simple & Moderate \\
\hline $\begin{array}{c}\text { The severity of the } \\
\text { disorder }\end{array}$ & moderate & $0.18679^{*}$ & \\
\cline { 2 - 4 } & strong & $0.23775^{*}$ & .005096 \\
\hline
\end{tabular}

The previous table showed that there are statistically significant differences in the play skills of autistic children between the simple severity of the disorder and the moderate severity of the disorder, in favor of the simple severity. Also, there are statistically significant differences in the play skills of autistic children disorder between the simple severity of the disorder and the strong severity of the disorder, in favor of the simple severity. The researcher attributes this result to the fact that children with simple severity of the disorder can be better able to social and communication 


\section{International Journal of Educational Research Review}

skills to perform skills play, it is worth noting that such skills often may be missed by children with moderate and strong severity of the disorder, these children have clear and distinctive behavioral problems that are stereotypical, restrictive and specific, and thus make their play behaviors characterized as stereotyped, restricted and specific. This result is inconsistent with the study of Hamdan (2017).

\section{Conclusions}

According to the findings, autistic children have communication difficulties; they are also characterized for their inflexibility of actions and difficulty adapting to change. This is due to the social interaction issues that these children face, which prevent them from paying attention to others or imitating their gestures, whether in play or elsewhere. These children are characterized by repetitive, restrictive, and unique behavioral traits that cause them to use toys in a routine and specific pattern, resulting in impaired coordination and visual-motor coordination abilities, which may be typical of many autistic children particularly in serious cases and cases accompanied by mental disorders. Based on the results revealed by the study, the researcher recommends emphasizing the importance of educating parents, teachers, and specialists on developing training programs that focus on developing play skills in autistic children.

This study focused on autistic children who are registered in private and government centers and institutes of Ministry of Education and the Ministry of Social Affairs in Jeddah for the academic year 2020/2021. The researcher suggests conducting more studies that include other related variables and studying another comparative group of people with disabilities, such as mental, visual, developmental delays and others.

\section{REFERENCES}

American Psychiatric Association (2013). From planning to publication: Developing the DSM-5. Timeline. Available at: http://www.dsm5.org/Documents/DSM\%205\%20development\% 20factsheet\%20116-13.pdf. Accessed February 6, 2006.

Brady, N., Fleming, K., \& Burke, K. (2012). Symbolic play of preschoolers with severe communication impairments with autism and other developmental delays: More similarities than differences. $J$ Autism Dev Disord. 42(5): 863-873.

Bryman, A., \& Bell, E. (2011). Business research methods. 3rd Ed. Oxford University Press. Oxford.

Bundy, A. (2012). Children at play: Can I play too. Kids can be kids: A childhood occupations approach. Philadelphia: FA Davis Company, 28-43.

Cesur, M. Ş., \& Odluyurt, S. (2019). An investigation of the opinions and suggestions of parents and teachers about the teaching of play skills to autistic children disorders. International Journal of Early Childhood Special Education, 11(2), 128-140.

Charlesworth, R. (2011). Understanding child development (9th ed.). Belmont, CA: Wardsworth Cengage Learning.

Cuevas, A., Febrero, M., \& Fraiman, R. (2004). An ANOVA test for functional data. Computational statistics \& data analysis, 47(1), 111-122.

Doody, K. R., \& Jana Mertz, M. B. A. (2013). Preferred play activities of autistic children in naturalistic settings. North American Journal of Medicine and Science, 6(3).

Fazlioglu, Y. (2013). The comparison of play skills of autistic mentally retarded and typically developing children. Educational Research and Reviews, 8(22),.2169-2175.

Flippin, M., \& Watson, L. R. (2011). Relationships between the responsiveness of fathers and mothers and the object play skills of autistic children disorders. Journal of Early Intervention, 33(3), 220-234.

Hamdan, M. (2017). The common play characteristics for autistic children disorder and its relation to some variables. An-Najah University Journal for Research-B (Humanities), 31(11), 3.

Hampshire, P. K., \& Hourcade, J. J. (2014). Teaching play skills to children with autism using visually structured tasks. Teaching Exceptional Children, 46(3), 26-31.

Hatzenbuhler, E. G., Molteni, J. D., \& Axe, J. B. (2019). Increasing play skills in autistic children disorder via peer-mediated matrix training. Education and Treatment of Children, 42(3), 295-319.

Jung, S., \& Sainato, D. M. (2013). Teaching play skills to young children with autism. Journal of Intellectual and Developmental Disability, 38(1), 74-90. 
Kent, C., Cordier, R., Joosten, A., Wilkes-Gillan, S., Bundy, A., \& Speyer, R. (2020). A systematic review and meta-analysis of interventions to improve play skills in autistic children Disorder. ReviewJournal of Autism and Developmental Disorders, 7(1), 91-118.

Kurkcuoglu, B. U., Bozkurt, F., \& Cuhadar, S. (2015). Effectiveness of instruction performed through computer-assisted activity schedules on on-schedule and role-play skills of autistic children. Educational Sciences: Theory \& Practice, 15(3).

Lam, Y. G., \& Yeung, S. S. S. (2012). Cognitive deficits and symbolic play in preschoolers with autism. Research in Autism Spectrum Disorders, 6(1), 560-564.

MacDonald, R., Sacramone, S., Mansfield, R., Wiltz, K., \& Ahearn, W. H. (2009). Using video modeling to teach reciprocal pretend play to children with autism. Journal of Applied Behavior Analysis, 42(1), 43-55.

Ray-Kaeser, S., Thommen, E., Baggioni, L., Stanković, M., Besio, S., Bulgarelli, D., \& StanchevaPopkostadinova, V. (2017). 10 play in autistic children and other neurodevelopmental disorders. In-Play development in children with disabilities (pp. 137-146). De Gruyter Open Poland.

Saunders, M., Lewis, P. \& Adrian, T. (2016). Research methods for business students.Pearson, ISBN-13: 9781292208787.

Szabó, M. K. (2014). Patterns of play activities in autism and typical development. A case study. Procedia-social and behavioral sciences, 140, 630-637.

Thiemann-Bourque, K., Johnson, L. K., \& Brady, N. C. (2019). Similarities in functional play and differences in symbolic play of autistic children. American journal on intellectual and developmental disabilities, 124(1), 77-91.

Vousden, B., Wilkes-Gillan, S., Cordier, R., \& Froude, E. (2019). The play skills of children with a highfunctioning autism spectrum disorder in peer-to-peer interactions with their classmates: A multiple case study design. Australian occupational therapy journal, 66(2), 183-192. 